\title{
INNOVATIVE APPROACHES IN DEVELOPING COMMUNICATIVE COMPETENCE
}

\author{
Olga Glushenko \\ Pskov State University, Russian Federation \\ Irina Korenetskaya \\ Pskov State University, Russian Federation \\ Ekaterina Kuznetsova \\ Institute of Foreign Languages, Saint Petersburg, Russian Federation
}

\begin{abstract}
The article deals with the aspect of the language acquisition through the use of socioculturally contextualized educational materials and applying particular strategies and techniques to improve communicative skills of the students. We have defined a motivationstimulating sociocultural principle, and presented both theoretical and practical items in terms of socioculturally contextualized educational materials based on the mentioned above principle. The social demand for a linguistically competent personality faces the problem of the lack of the proper effective educational methods in the classroom. The aim of the research is to study the theory and practice of developing the communicative competence via the innovative approaches in language education. The article also introduces the concept of multiculturalism and global citizenship, national values and beliefs in language education as innovative principles of education, interest to a human being and to another culture as a life skill, we study the definitions of multiculturalism and the phenomenon of interest to a personality, we, identify various types and components within the complex structure of multiculturalism; describe the ways of applications of the principles of multiculturalism into the classroom. We also suggest a model of developing the communicative competence through innovative approaches (with stages, particular algorithms for a teacher, indicators in students' behavior).
\end{abstract}

Keywords: global citizenship, motivation, multiculturalism, sociocultural awareness, socioculturally contextualized educational materials, values.

\section{Introduction}

In our increasingly globalised world language teaching for developing communicative competence and intercultural communication is front and center in the educational mission of facilitating the students' participation in intercultural citizenship which is a "sine qua non" in today's society (Byram, 2018). To become a successful person, to prosper economically, and to have positive relations with the representatives of other nations the students should be able to read, speak, and understand other languages. However, focusing only on linguistic 
aspects of the language is not enough. The educators should help their students acquire and apply linguistic and communicative competence.

The paper deals with the innovative approaches of fostering students' (multilingual and multicultural) identities by developing the existing and new language skills and identities through interactions with the representatives of other cultures. The subject under consideration is motivated by the great changes the world has been going through for the past several decades. New conditions of a technologically developed, multicultural, multinational society provide a new focus for intercultural communication. Thus, an effective system of training is becoming increasingly in demand.

\section{The concept of multiculturalism at the English classroom}

The study shows that the problem originates from the outdated strategies and techniques currently applied during the instructional process. They have proved to fail in fostering students' intellectual and emotional capacity. Neither do they motivate them or develop communicative competence in a foreign language.

Following that reasoning, effective strategies and techniques for mastering a foreign language under new conditions should be offered. Let's consider multicultural approach for developing communicative competence at a foreign language classroom. It originates from the necessity to develop tolerant, effective, fruitful and responsible global citizenship. The teacher should provide particular tools to help students become successful in modern society and learn to perform in multicultural encounters. What can give the students new insights into their own culture and another culture is multicultural awareness as well as selfawareness. A single generally accepted interpretation of the term "multiculturalism" is not available at the moment. Multiculturalism is understood as the recognition and promotion of cultural pluralism. Multiculturalism advocates cultural diversity. Finally, multiculturalism can be interpreted as the coexistence of several cultures within one group, and also as a policy aimed at ensuring equal opportunities for different cultures and combating discrimination against minority cultures.

In global studies various adjectives are used to describe education in the context of existing cultural diversity: cross-cultural, metacultural and multicultural. These labels or markings are used interchangeably, often without differentiation of values. In this multicultural and intercultural are the most common concepts in education and many researchers and practitioners have attempted to determine precisely their key characteristics and the boundaries of these concepts. Some European researchers are inclined to attribute the notion of multiculturalism some negative characteristics, arguing that multicultural education exacerbates cultural differences and ignores the similarities, 
individuality and significance of interrelations and interaction of cultures, in contrast to intercultural education. Culture is behavior, beliefs and values (Wagner, 2017). Consequently, communicative competence combines language skills with the knowledge, personal experience, attitudes, that help become "intercultural citizens".

In this paper, we deal with multicultural and intercultural awareness with regard to the concepts of culture and identity.

Therefore, the optimal definition of multiculturalism in education should go beyond the traditional context of multicultural education and should include a methodology for the formation of knowledge, communicative skills in general and skills of intercultural communication in diverse contexts.

In the Western approaches, multiculturalism is often defined as communication among cultures, among people representing different cultures, between a representative of one culture and a carrier of information (digital, paper) in a different culture.

Teaching "culture" is a part of "language teaching”. However, teaching culture exclusively as information about a country and nation is wrong. Culture is a complicated and challenging concept, difficult to define.

We strongly support the idea of $\mathrm{M}$. Byram, who suggests that an interculturally competent speaker is someone who has skills of discovering about one's own culture and another culture, comparing the aspects of another culture with our own culture to get better understanding, analyzing and evaluating the elements of cultures (Byram, 2000).

Effective communication becomes possible only if participants share common values and find common cultural grounds for communication (if there is a "third culture", a shared culture, a compromise reality, a multicultural hybrid culture).

There are certain pedagogical tools for the formation of relationships of multicultural awareness in the group of students as a specially organized educational process characterized by a sequence of stages and developing the spiritual (value content of consciousness) and the soul (value content of experiences) characteristics of a personality.

We suggest a model of pedagogical support for the developing of multicultural awareness at a foreign language classroom, with the target, stages, content (algorithm of teacher's actions in the classroom) and the result.

At every stage the students work with the texts (written or video) and find the answers to the following set of questions (presented by Byram M., 2018): Whose words are those? Whose discourse? Whose interests are being served by this text? What made this text possible and another impossible? How does the speaker position him/herself? How does he/she frame the events talked about? What prior discourses does he/she draw on? 
Stage 1. Inclusion. At this stage the teacher assists the students in the acquiring the skills of a positive attitude and interest to the problem of multicultural awareness through the demonstration in the process of open communication the significance of this phenomenon. Emotional inclusion is achieved through the use of particular speech clichés: "I'm interested in it", "I want to participate in it", "I want to understand", "I want to be understood". At the stage of inclusion the workshops with the following topics can be held: "Me and my group mates", "Happiness is when you are understood", "Everyone chooses for himself" (about spiritual values in the life of a person), "The House of Our Happiness" (value attitudes and happiness in the classroom), etc., where the students are offered to answer the questions like "Who understands me?", "Whom do I understand?", "How do my relationships develop with those who understand me and whom I understand?". At the class "We are going to a birthday party" students reflect on what they know about a person, his/her dreams, hobbies, nature, favorite pursuits, in order to give him/her a birthday present. As a result, there is a shift in the attitude of students towards the problem of understanding people in their statements: "To understand a representative of another culture is an opportunity to make the relationship better and kinder", "Multicultural awareness is the key to happiness", "For the first time I thought about who understands me and whom I understand", "Multicultural awareness eliminates the conflicts".

Stage 2. Problem-setting. At this stage the problem of multiculturalism becomes personally significant. The teacher expands and enriches the ontological basis of multicultural relationships among students through joint search, discovery and insight into the new values of multiculturalism; in the process of working on the content of the basic philosophical postulates and metaphors: "to understand a culture is to justify", "without understanding there is no acceptance of an individual, and without acceptance there is no and can not be interaction in multicultural encounters", "understanding a person is possible only through experience", "attention generates interest to a person, and there is nothing more interesting than a human being in the world", etc. The students discuss the essence of multiculturalism as the basic mode of being; differentiate the notions of understanding and knowledge, understanding and explanation; accept another person as he/she is; accept the values of another person.

The stage of problem-setting was devoted to the discussion of the following issues: "Multiculturalism and Conflict", "Components of multicultural awareness and relationships"; communicative exercises like "Sincere joy", "Verbal portrait", "What the eyes say", "Catch the mood of the class", "I'm responsible for you" are held; workshops such as "On the way to multiculturalism", "Multicultural awareness is the path to harmony" are organized. As a result, the statements and creative works of students at this stage become more sophisticated: "a person can 
not be explained, he/she can be understood and described", "multicultural awareness and understanding relationships are the basic way of being, working with meanings, accepting a person as he is, justifying him", "to read the text, you need to know the alphabet, a person can also be "read", but for this you need to know the "ABC" of multiculturalism", "multicultural awareness is an art".

Stage 3. Action. At this stage students become aware of the behavior strategies. The teacher organizes the activities that lead to the maintenance of interest and the need to be understood and understand the representative of a different culture. It is realized through the interpretation of texts, photographs, movies and TV shows; analysis of encounters with a beautiful, tragic, unusual, a situation of choice and a situation of resistance to the negative: a) the teacher introduces the cultural text into the sphere of interaction; b) sets a problem by revealing contradictions and asks participants to strengthen the problems by finding, opening up other contradictions, paradoxes of misunderstanding; c) challenges the understanding of everyone and leads the participants into a reflexive position in relation to their variant of understanding; e) the arising conflict of semantic positions is used as a basis for the beginning of polypositional communication; g) mutual understanding. The students start to show interest and attention to the person ("empathic listening"); they extract the meanings from the life manifestations of a person and interpret them on the basis of their own life experience, but taking into account the values of another person; they are engaged in a multicultural dialogue; they can "transfer" themselves to the position of another person; they are aware of the similarity and difference of human individualities.

The core of the meetings were problem situations, examples that lead to different aspects of the activity-behavioral component of mutual understanding relationships (the film about Tom Sawyer - the episode where the character paints the fence, showing himself as a small manipulator; the reflections of a famous surgeon Fyodor Uglov on good and evil; a television interview of figure skater Arthur Hill about the attitude to fame, live-show "Dom-2", where love is a bargain and business alliance). At this stage, the students completed the tasks: "Group agreement on multiculturalism”, "The Dictionary of Multicultural Relationships”, "Declaration of Principles of Multicultural Relationships".

The comprehension of the problem of multiculturalism goes beyond the classroom, when students, preparing for classes at home, address their parents and friends, formulate together the principles of the successful life of the multicultural group, prepare fragments of works of art, films, television programs illustrating cases of multicultural relationships or misunderstanding, make a code of behavior in multicultural environment, write essays, stories, articles, dictionary entries about multiculturalism. 


\section{Intercultural communicative competence in the context of the socioculturally contextualized materials}

The communicative competence is closely related to the motivation for learning and its consistency, as well as to a high level of interest that has to be constantly maintained. Theoretical significance of our research leads to the further development of the concept of motivated foreign languages teaching/learning via incorporating socioculturally contextualized educational materials. Within this new context, we are guided by a new principle defined as "motivation stimulating sociocultural principle", which enables the educators to put intercultural communicative competence into a context.

By socioculturally contextualized educational materials we mean multimedia tools (musicals in particular) used for maintaining and stimulating motivation for learning a foreign language, and for creating favorable conditions for formation and developing communicative competence. Involving multimedia tools in educational process creates conditions for modeling a specific educational environment in the process of teaching foreign languages. In this context, multimedia materials acquire the quality of socioculturally contextualized educational materials. These audiovisual authentic materials correspond to all psychological and pedagogical demands needed for the successful formation of motivation. First, they affect the emotional dynamic of the audience. Second, they function as a powerful tool to stimulate the awareness of the need for learning and to promote the formation of the motive. Finally, these materials carry a significant potential for learning and raise the awareness of the aesthetic value of a foreign language communicated through various linguistic and cultural information.

We believe that one of the effective mechanisms for developing a foreign communicative competence is the integration of the socioculturally contextualized educational materials into the teaching/learning process. The methodical emphasis of our research is placed on integrating authentic films (musicals) into the pedagogical reality. The strategy of incorporating foreign films into the teaching/learning process provides the following benefits:

- the increased emotional impact of a foreign language authentic text on the listener;

- a way to obtain verbal information with no difficulty through foreign language 'immersion';

- a way to obtain non-verbal information as the conditions for the formation of a proper language behavior (model) in a foreign language environment are provided for.

The suggested strategy assumes direct participation of the students in the teaching/learning process. At the same time, the essence of educational process is 
the expansion of sociocultural awareness via the use of multimedia tools and students' independent work. The basis of the language training is the emotional accessibility of video materials and the development of interaction and cooperation skills. The peculiarity of our technique implies the students' involvement into an efficient activity designed by the instructor. This techinique is based on psychological and pedagogical aspects of the formation of motivation in the process of studying a foreign language. It also relies on the qualities of the proposed socioculturally contextualized educational materials used for educational purposes in terms of the formation of the educational motivational basis. The fundamental principle in the system of teaching via multimedia, "a motivation stimulating sociocultural principle", aims at increasing the role of motivation.

The content of the multimedia materials is also determined by the following methodological principles: 1) authenticity of video production; 2) methodologically expedient use of materials; 3) communicative and contrasting nature of native and foreign cultures; 4) cultural compatibility; 5) emotional accessibility or emotional connections for learning; 6) the principle of incentive management.

Taking into account all the above principles, we propose the following criteria for the selection of video materials:

1. Authenticity of video production.

2. Consistency with the academic curriculum.

3. Consideration of the possible language difficulties.

4. Artistic value of the video production

5. The proposed video materials' potential for the discussion.

6. Correlation to classical literature

7. Consideration of the psychological and pedagogical characteristics of the audience.

8. Humanistic nature of the video production.

Taking the mentioned above criteria into consideration, we focus on a musical film (musical), and propose the following repertoire for pre-view, viewing and further types of work:

Film 1. Chitty-Chitty Bang-Bang (Ian Fleming)

Film 2. Les Miserables (Trevor Nunn)

Film 3. The Phantom of the Opera (Joel Schumcher and Andrew Lloyd

Webber)

Film 4. The Sound of Music (Richard Rogers and Joel Schumacher)

Film 5. My Fair Lady (George Cukor)

Film 6. The King and I (Richard Rogers and Oscar Hammerstein II)

Film 7. Cats (Lloyd Webber and Trevor Nunn)

Film 8. Moulin Rouge (Baz Luhrmann) 
Film 9. Dancer in the Dark (Lars von Trier)

Film 10. Jesus Christ Superstar (Andrew Lloyd Webber, Tim Rice)

Film 11. Dirty Dancing (Eleanor Bergstein)

Film 12. Beauty and the Beast (Alan Menken, Howard Ashman, Tim Rice)

Film 13. Chicago (John Kander, Fred Ebb)

Film 14. Chess (Benny Andersson, Bjorn Ulvaeus, Tim Rice)

Film 15. Evita (Andrew Lloyd Webber, Tim Rice)

Our technique involves the application of musicals from the given repertoire, and include the sets of the following training activities that consist of three stages:

1) speech-stimulating or warming activities,

2) watching activities,

3) speech-forming activities.

Stimulating or warming exercises aim at optimizing conditions for motivational considerations. Watching exercises aim at understanding video materials. Speech-forming exercises aim at forming motivation in the learning process and developing communication skills. Generally, three blocks of exercises are suggested in accordance with the stage of work:

1) speech-stimulating or warming activities, such as studying new vocabulary, finding Russian/English equivalents for some words or word combinations, working with idiomatic expressions presented in the film, matching the words and phrases, giving a free translation of the articles devoted to the film;

2) watching exercises, such as designing a plan of the film, anticipation of the further information, "stop-slide and talk", cinema scoring, performing songs;

3) speech-forming exercises, such as rendering the plot and describing the characters of the film, composing dialogues for imaginary situations, doing case-study tasks and projects, writing essays, participating in oral discussions and debates, role plays, dramatizing.

The purpose of the first block of exercises is to challenge the students' interest and to stimulate further learning activities. The purpose of the second block of exercises is to enhance listening skills and understanding of the content of the film. The purpose of the third block of exercises is to allow students to experiment with the language, support pair and team work, and on the whole, receive a constructive feedback in a controllable educational environment.

Incorporating socioculturally contextualized educational materials (musicals) into a teaching/learning process helps learners to observe the natural way of social interactions. The strategies we suggest enable learners to achieve deep analyses and to develop deeper understanding of the language in use, which in its turn can help them to note the gaps and to achieve learning readiness. 
The sequence of implementing theoretical aspects regarding the efficiency of incorporating audio-visual aids to promote motivational background is as follows:

- application of a foreign language musical video series;

- $\quad$ modeling of the positive emotions;

- developing motivation for taking actions;

- formation of the communicative competence;

- $\quad$ stimulating creative activities (Glushchenko, 2012).

\section{Intercultural skills acquisition via the project methodology}

The implications for language teaching by means of project methodology may be as follows: develop explicit purposes for intercultural interaction; introduce strategies to draw on critical awareness raising and collective sensemaking to help students to enhance their intercultural experience to develop intercultural competence and global citizenship; develop a systematic approach to cultural preparation including the socio-political-cultural and historic context; work with particular texts according to the hot issues of the future profession, rendering the texts, application of knowledge gained in the process of researching foreign resources for other professional disciplines (CLIL).

Analyzing various issues from different cultural views, realizing that other cultures tend to perceive things differently, possess other values and beliefs, is one of the most valuable experiences that CLIL may offer. Students need to learn about other countries because there is evidence that people's willingness to interact greatly increases the better they know each other. If we want to prepare our students to succeed in a globalized word and enable them to work in teams across national and cultural borders, intercultural communicative competence needs to be the ultimate educational target and it must be placed at the front of our teaching.

Thus, the following goal is achieved: by learning foreign languages, students have the opportunity to become familiar with other cultures. Such insight provides the basis for respect and increased tolerance, and contributes to other ways of thinking and broadens students' understanding of their own cultural belonging. In this way students' own identity is strengthened.

Project technology enables the students to acquire critical cultural awareness, i.e. an ability to evaluate, critically and on the basis of explicit criteria, perspectives, practices and products in one's own and other cultures and countries.

At the heart of the project technology there is the development of cognitive skills and intercultural skills of the students; the ability to search in the 
information space, the ability to shape the knowledge on their own, integrate knowledge from various fields of science, and critical thinking.

Participation in project activities in the foreign language classroom develops critical thought, development of self within traditions, mutual understanding and development of traditions, self-reflection, self-monitoring to given standards and norms. If a learner receives intercultural skills of orientation in the amount of information in the course of work at a foreign language project, he/she will learn to analyze it, generalize, see the trends, compare the facts, draw conclusions, then due to the higher educational level it will be easier to adapt in the changing conditions of the surrounding reality, the students will be creative and analytical in finding the solution of various problems in everyday life encounters.

In modern conditions we can use a wide range of topics, project variants and ways of implementing them, opportunities of modern interactive technologies, presentations, blogs, video clips and so on in a foreign language classroom.

It should be noted that the projects are of different types and, depending on the purpose of the assignment, the teacher will choose the most effective in this particular situation: research projects, creative, role and game projects, information, practice-oriented projects, as well as mono-projects within a single subject, inter-subject projects and international ones.

\section{Conclusion}

To draw a conclusion, we can say that intercultural skills as well as knowledge are required for students' communicative competence. Moreover, the former idea, when students had to imitate the native speaker in the Englishlanguage classroom, completely fails, as it is not only the matter of knowledge of language but values, which can hardly be copied. Intercultural and communicative competence is a combination of attitudes, knowledge, understanding and skills applied through interaction which enables one to understand, accept, respect people with different values; respond appropriately, effectively, and respectfully; establish positive relationships; understand the differences and similarities of the representatives of different cultures. developing communicative competence in a foreign language classroom through the mentioned above approaches is a specially organized education process aimed at both developing linguistic skills and the ethno-cultural identity of a person via familiarization with the native language and culture, while simultaneously absorbing the cultural and spiritual values of other people and the achievements of the world culture.

Education based on the stated in the material principles, contributes to the preservation and development of the diversity of cultural values and cultural practices, helps the formation of the cultural identity of the individual; promotes 
the perception and respect for cultural diversity, as well as intercultural interaction and community integration.

Finally, the principles of multiculturalism, intercultural citizenship, understanding and accepting other values, beliefs, ways of interaction should become a part of internationalization of higher education, where the "mutual understanding approach" should be a vital priority and a contribution to person's ability to communicate, interact, collaborate and contribute globally.

\section{References}

Byram, M. (2000). Assesing Intercultural Competence in Language Teaching. Sprogforum 18 (6), 8-13.

Byram, M. (2012). Language awareness and (critical) cultural awareness-relationship, comparison and contrasts. Language Awareness, 21 (1-2), 5-13

Byram, M., \& Wagner M. (2018). Making a difference: Language Teaching for intercultural and International Dialogue. Foreign Language Annals. 2018; 1-12. Retrieved from https://doi.org/10.1111/flan.12319

Glushchenko, O. (2012). Optimising Conditions for Motivational Considerations in eveloping Socio-Cultural Competence of Students of Non-Language Departments by Means of Audio-Visual Aids. Innovative Methods in Multicultural Education. Narva College of the University of Tartu.

Wagner, M. (2017) Teaching Intercultural Competence Across the Age Range. Multilingual matters. 